\title{
Why Do Our Kidneys Get Old?
}

\author{
Jocelyn Wiggins \\ Division of Geriatrics, Internal Medicine, University of Michigan, Ann Arbor, Mich., USA
}

\section{Key Words}

Biology of aging $\cdot$ Renal function - Calorie restriction • Glomerulosclerosis • Cellular senescence • Autophagy • Telomere $\cdot$ Klotho

\begin{abstract}
The majority of the human population shows a decline in renal clearance with age and a loss of renal physiologic reserve. Kidneys are increasingly less able to deal with stressful challenges such as a salt or acid load. It is not clear what underlies this aging-related change and whether it is inevitable or can be modified in such a way as to preserve renal function throughout the life span. This is a very brief review of aging biology and how it might impact on renal aging.
\end{abstract}

Copyright $\odot 2011$ S. Karger AG, Basel

US Census data show that the oldest age groups are the fastest growing segment of the US population, and a similar trend is also seen in European countries and in Japan [1]. There have been very steady gains in life expectancy over the last half century, with a very considerable increase in the utilization of health care services. It has been known for over 50 years that renal function declines with age and that glomerulosclerosis increases with age even in the absence of comorbidities. The Baltimore Longitudinal Study of Aging was started in 1958 and they collected both cross-sectional and longitudinal data on changes in renal function with age [2]. They estimated that creatinine clearance declines about $10 \mathrm{ml} / \mathrm{min}$ per decade after age 40 , and this continues to be true. NHANES data estimate that approximately $11-13 \%$ of the US population has decreased glomerular filtration rate and this may be as high as $30 \%$ in the older population [3]. Glomerular filtration rate declines with age even in healthy individuals. This article will briefly define some of the issues related to 'normal aging' biology and how it may contribute to the decline in renal function with age. Serious research into the biology of aging is a very young field. Decline in tissue function and vitality was assumed to be the inevitable consequence of a life time of wear and tear and thus not worth studying. Aging is now known to be a complex biological process controlled by signaling pathways and transcription factors. In this section I will review what is known about the biological mechanisms of aging and how these might be relevant to the changes in kidney function that occur in our patients with age.

\section{Calorie Restriction}

The only well-established way to increase life span and reduce aging-related disease burden is calorie restriction. Calorie restriction has been known to increase life span since 1935, when McCay et al. [4] published a rodent study that showed reducing calories without malnutrition extended both average and maximum life expectancy. Over the intervening years, work on calorie restriction

\section{KARGER}

Fax +4161306 1234

E-Mail karger@karger.ch

www.karger.com
(C) 2011 S. Karger AG, Basel

$1660-2129 / 11 / 1195-0001 \$ 38.00 / 0$

Accessible online at:

www.karger.com/nee
Jocelyn Wiggins

Division of Geriatrics, Internal Medicine

University of Michigan

Ann Arbor, MI 48109 (USA)

Tel. +1 734615 0143,E-Mail wiggi@ umich.edu 
and its mechanism was limited mainly to short-lived organisms such as yeast, worms and flies. In the 1980s, the National Institute on Aging set up a series of studies in rodents to look at mechanisms of aging and the retardation of aging-associated pathologies, and not just extension of life span. The National Institute on Aging developed specific colonies of aging mammals and systematically characterized the aging process in rodents, comparing animals fed ad libitum to their calorie-restricted litter mates. They established guidelines for the nutritional management of calorie restriction and continued to supply calorie-restricted animals and appropriate chow to funded projects [5-7]. Most recently, Colman et al. [8] have published the results of a 20-year longitudinal study of calorie restriction in primates. They observed the effect of calorie restriction on the resistance to age-associated illness as well as the effect on mortality. They reported a 3-fold increase in the onset of age-associated diseases in animals fed ad libitum as compared to the calorie-restricted animals at any given age and a significant increase in life span. They specifically studied onset of diabetes, cancer, cardiovascular disease and brain atrophy as these are common diseases of aging in man, but did not look at renal disease. However, we do know that calorie restriction in rats reduces mesangial matrix expansion, proteinuria and prevents the development of age-associated glomerulosclerosis [9].

\section{Cellular Processes}

Many cellular processes have been implicated in the aging process, although none have resulted in therapeutic options to slow aging. Epigenetics is the process whereby cells are directed to differentiate into the specialized cells that constitute the individual tissues. During nephrogenesis, regulatory genes divide the genome into active and inactive domains to control cell fate. This process is also important for the maintenance of cellular phenotype. Through the process of methylation and acetylation, these changes in the genome become both stable and heritable. In this way, cell lineage becomes established and phenotype is maintained. Once differentiation is established, it is self-maintaining. In the kidney, this process allows for the differentiation of a multitude of cell types all along the nephron and the collecting system. How does epigenetics affect aging in the kidney? In cells that divide on a regular basis, these epigenetic determinants are renewed at each cell division. Podocytes and other nondividing cells probably do not replicate so that they need to maintain their epigenetic characteristics throughout a life time. If their epigenetic marks are unstable over time, you would expect to see both a loss of characteristic phenotypic proteins and/or expression of proteins that should have been silenced. In the Fischer 344 rat model of aging, both of these changes in expression are seen in the glomerulus with normal aging [10]. In addition, Lefevre et al. [11] have changed the expression of methylation pathways specifically in the podocyte after normal differentiation has happened. As these animals age, they start to develop proteinuria and, by 12 months of age, their protein-to-creatinine ratio is 30 times that of the control rats. On light microscopy, they show both glomerulosclerosis and interstitial fibrosis. Electron microscopy demonstrates disorganized foot process structure with both irregular interdigitation and flattening and fusion of the foot processes. Thus, epigenetics plays an important role not just in the differentiation of cell types within the kidney but in the maintenance of phenotype and normal cellular function as we age.

Other cellular processes have also been shown to play a role in aging. MicroRNAs (miRNAs) are one of the newest areas in regulatory biology. The first miRNA was discovered in 1993. The role of miRNAs in cell senescence and aging is reviewed in detail by Grillari and GrillariVoglauer [12]. Harvey et al. [13] showed that disruption of miRNA leads to rapid end-stage kidney disease in mice. As yet, there are no specific data on the role that they play in aging in the kidney, but as more evidence accumulates about the role they play in differentiation, cellular function and disease, it is only a matter of time before their role in the aging kidney is defined.

Mitochondria are the intracellular organelles that produce energy in the form of ATP through oxidative phosphorylation. They also appear to play an important role in the cellular death, or apoptosis, pathway. Although the majority of mitochondrial proteins come from nuclear DNA, mitochondria contain some of their own DNA. The mutation rate in mtDNA is 10 times higher than that of nuclear DNA since mitochondria lack protective histones or repair mechanisms. Kidney cells participate in many energy-rich functions such as ion pumps, and transportation of low-molecular-weight proteins and vitamins. This makes the kidney particularly susceptible to mitochondrial damage. There are no specific data at this time on the role mitochondria play in aging in the kidney. However, it is likely that mitochondrial dysfunction contributes to the vulnerability of older patients to acute kidney injury. Mice that have been engineered to accumulate 
mitochondrial DNA mutations show reduced electron transport chain function, signs of accelerated aging and shortened life span [14]. Declining mitochondrial function seems likely to play a role in aging in the kidney.

There is a well-developed body of literature on the role of oxidants in the aging process [15-17]. Oxidative damage arises both from cellular oxidative metabolism and from oxidized content in the diet $[18,19]$. Animal models of high oxidant load, including hypercholesterolemia, high-fat diets and scavenger receptor defects all develop chronic kidney disease as well as atherosclerosis and cardiovascular disease $[20,21]$. In the kidney, ceruloplasmin, a powerful antioxidant, is produced by parietal epithelial cells lining Bowman's capsule in response to aging and ad libitum feeding and is reduced by calorie restriction with its lower oxidant load [22]. This would suggest that the kidney has its own mechanism of defense against oxidant damage and that this plays a role in preserving renal function.

Autophagy is the process whereby damaged proteins and organelles are delivered to the lysosome for disassembly and recycling. This process allows nondividing cells, such as podocytes to deal with damage caused by oxidation, misfolding or any other protein pathology. Failure to maintain cell integrity is associated with dysfunction and aging [23]. In mice, podocyte-specific knockouts of players in the autophagy pathway have been created [24]. These mice show accelerated glomerular aging with accumulations of oxidized and ubiquinated proteins, endoplasmic reticulum stress and proteinuria, and ultimately late-onset glomerulosclerosis. A 10 -fold increase in urine protein-to-creatinine ratio was seen in 20 -month-old mice with a 5 -fold increase in glomerulosclerosis. Damaged proteins and organelles accumulated in the podocytes and had a detrimental effect on cellular homeostasis, and the authors showed a decline in podocyte numbers per glomerulus compared to controls by 22 months. Declines in autophagy proteins have been demonstrated in biopsies of people with glomerular diseases [24].

Telomeres are specialized structures at the ends of chromosomes. They are vital for chromosome stability and maintenance of chromosome length during cell division. The complex of molecules that orchestrates replication of DNA sits at the end of the chromosome sequence so that this area does not get copied. Thus telomere length dictates cell life span, as each round of DNA replication results in successive telomere shortening until the telomeres become critically shortened, resulting in cellular crisis. An excellent review by Campisi [25] outlines the current understanding of the relationship of cellular senescence, tumor suppression and organism aging. How is this complex cell biology relevant to the kidney? Westhoff et al. [26] have studied the role of telomeres in ischemia-reperfusion injury in telomerase-deficient mice. They compared fourth-generation mice with first- and second-generation mice. As the telomeres shortened through the generations, mice demonstrated reduced proliferative capacity in tubular, glomerular and interstitial cells. They were more vulnerable to acute kidney injury and less likely to regenerate tubular epithelium. They mimicked older patients, who are significantly more susceptible to acute renal injury and less likely to recover renal function following such an injury. Feest et al. [27] have shown that there is a progressive age-dependent increase in acute kidney injury in man after age 60 , but there is no direct evidence to support a role for telomeres in the decline of renal function with age.

Maintaining the integrity of DNA is essential for healthy cellular wellbeing. Mutations that lead to accelerated aging are usually localized to the genes responsible for DNA repair, replication and transcription. The best studied of these premature aging syndromes, known as progeria, are due to mutations in helicases which are responsible for reading and checking and repairing the integrity of DNA. Although none of the progeroid syndromes exactly match physiological aging, studies of these syndromes are yielding clues to how DNA damage, which accumulates with age, may play a role in the aging process [28]. There is one report of kidney pathology related to progeria. It describes renal histopathology of 2 subjects who died from progeria. The younger subject who died aged 11 years had no glomerulosclerosis, while the kidney from the 20-year-old subject showed focal renal scarring with focal glomerulosclerosis and associated tubular atrophy, similar to that seen in physiological aging [28].

\section{Individual Aging Genes}

There are four individual genes that have been shown to impact life span and the aging process. They are insulin-like growth factor (IGF-1), target of rapamycin (TOR), sirtuins and klotho. Prolonging life span by interfering with IGF-1 pathways has been studied in many experimental organisms and there are cohorts of centenarians in which mutations affecting activity in IGF-1 signaling have been shown [29]. There is currently no known link to the kidney. The TOR pathway senses the availability of 
food and nutrients and controls growth and development. TOR inhibition increases life span in all experimental models from yeast to mammals [30]. It is the pathway that is implicated in calorie restriction, and if you subject a TOR-transgenic animal to calorie restriction, you do not get further extension of life span [31, 32]. Experiments are currently under way in mice to try and extend life span by using rapamycin [33]. There is currently no known link to aging in the kidney. The sirtuin pathways are believed to be the target of resveratrol, the much touted 'healthy ingredient' in red wine. There are $7 \mathrm{mam}$ malian sirtuin enzymes called SIRT1-7 [34]. In knockouts of at least one family member, SIRT6 causes premature aging [35]. This is a rapidly expanding field with, as yet, no link to the kidney. Klotho was the Greek goddess who spins the thread of life and the name was given to a gene that characterized a rapid and premature aging phenotype. Klotho is expressed as both a membrane protein and a secreted protein, primarily in the distal tubular cells of the kidney. Its primary role appears to be as a cofactor or coreceptor-regulating fibroblast growth factor 23 signaling and activation of the ion channel TRPV5. It plays an important role in phosphorus homeostasis. Klotho promotes phosphate excretion and reduced expression of klotho is associated with ectopic calcification, increased concentrations of $1,25(\mathrm{OH})_{2} \mathrm{D}_{3}$, hyperphosphotemia and therapy-resistant hyperparathyroidism $[36,37]$. Though these functions are important in the context of renal disease, the rapid-aging phenotype appears to be modulated through the IGF-1 signaling pathway. Reduced expression of klotho has been observed in patients with chronic kidney disease. Some single-nucleotide polymorphisms (individual DNA variation) in human klotho are associated with altered life span and increased vascular disease [38]. Klotho is clearly an interesting protein with a role to play in the complications of chronic kidney disease and maybe in the altered life span associated with this disease.

\section{Animal Models of Extended Life Span}

In the 1980s, two long-lived dwarf mouse strains were discovered: the Ames and Snell dwarf mice [39]. Both of these were spontaneous mutations. These mice lack growth hormone, prolactin and thyroid-stimulating hormone due to disruption of a common transcription factor necessary for all of these pathways. They are not only smaller than their litter mates but live $65 \%$ longer. These mice also show a delay in aging-related diseases. There are now seven genetic mouse models of delayed aging. While there is no clear understanding of how these models confer extended life span, research on these models is extending our understanding of the aging process. Recent data suggest that reduced signaling of the IGF-1 pathway may play a role [40]. While these models are clearly interesting from a scientific perspective, they do not offer realistic therapeutic avenues for managing aging and age-associated pathologies in people.

The biology of human aging is a highly active and rapidly evolving field. At this point in time, there are as many questions as there are answers. In addition to these basic aging processes, there are changes in the biology of the kidney as the cells age. Superimposed are the agingrelated changes in the body's hormone environment. The kidney is also highly vascular and is impacted by aging of the vascular system with the development of atherosclerosis and hypertension. Clarifying the individual role of all of these interacting processes is a challenge for the next generation of investigators. At this time, with the exception of calorie restriction, we have no real therapeutic options for slowing the progression of renal aging and its associated pathology.

\section{Disclosure Statement}

The author has no conflicts of interest to declare.

\section{References}

1 National Vital Statistics Reports. Centers for Disease Control and Prevention, National Center for Health Statistics, National Vital Statistics System, 2006, vol 54, No 14.

2 Lindeman RD, Tobin J, Shock NW: Longitudinal studies on the rate of decline in renal function with age. J Am Geriatr Soc 1985;33: 278-285.

3 Coresh J, Astor BC, Greene T, et al: Prevalence of chronic kidney disease and decreased kidney function in the adult US population: Third National Health and Nutrition Examination Survey. Am J Kidney Dis 2003;41:1-12

4 McCay CM, Crowell MF, Maynard LA: The effect of retarded growth upon the length of life span and upon the ultimate body size. Nutrition 1935;5:155-171.

5 Yu BP, Masoro EJ, McMahan CA: Nutritional influences on aging of Fischer 344 rats. I. Physical, metabolic and longevity characteristics. J Gerontol 1985;40:657-670.

- 6 Maeda H, Gleiser CA, Masoro EJ, Murata I, McMahan CA, Yu BP: Nutritional influences on aging of Fischer 344 rats. II Pathology. J Gerontol 1985;40:671-688.
Wiggins 
7 Masoro EJ: Dietary restriction and aging. J Am Geriatr Soc 1993;41:994-999.

-8 Colman RJ, Anderson RM, Johnson SC, Kastman EK, Kosmatka KJ, Beasley TM, Allison DB, Cruzen C, Simmons HA, Kemnitz JW, Weindruch R: Caloric restriction delays disease onset and mortality in rhesus monkeys. Science 2009;10;325:201-204.

-9 Wiggins JE, Goyal M, Sanden SK, Wharram BL, Shedden KA, Misek DE, Kuick RD, Wiggins RC: Podocyte hypertrophy, 'adaptation', and 'decompensation' associated with glomerular enlargement and glomerulosclerosis in the aging rat: prevention by calorie restriction. J Am Soc Nephrol 2005; 16:29532966.

10 Wiggins JE, Patel SR, Shedden KA, Goyal M, Wharram BL, Martini S, Kretzler M, Wiggins RC: NFKB promotes inflammation, coagulation, and fibrosis in the aging glomerulus. J Am Soc Nephrol 2010;21:587-597

-11 Lefevre GM, Patel SR, Kim D, Tessarollo L, Dressler GR: Altering a histone H3K4 methylation pathway in glomerular podocytes promotes a chronic disease phenotype. PLoS Genet 2010;6:e1001142

12 Grillari J, Grillari-Voglauer R: Novel modulators of senescence, aging and longevity: small non-coding RNAs enter the stage. Exp Gerontol 2010;45:302-311.

13 Harvey SJ, Jarad G, Cunningham J, Goldberg S, Schermer B, Harfe BD, McManus MT, Benzing T, Miner JH: Podocyte-specific deletion of Dicer alters cytoskeletal dynamics and causes glomerular disease. J Am Soc Nephrol 2008;19:2069-2075.

- 14 Edgar D, Trifunovic A: The mtDNA mutator mouse: dissecting mitochondrial involvement in aging. Aging (Albany NY) 2009;1: 1028-1032.

15 Muller FL, Lustgarten MS, Jang Y, Richardson A, Van Remmen H: Trends in oxidative aging theories. Free Radic Biol Med 2007;43: 477-503.

16 Ferrucci L: The Baltimore Longitudinal Study of Aging (BLSA): a 50-year-long journey and plans for the future. J Gerontol A Biol Sci Med Sci 2008;63:1416-1419.

- 17 Vlassara H, Uribarri J, Ferrucci L, Cai W, Torreggiani M, Post JB, Zheng F, Striker GE: Identifying advanced glycation end products as a major source of oxidants in aging: implications for the management and/or prevention of reduced renal function in elderly persons. Semin Nephrol 2009;29:594-603.
8 Makita Z, Yanagisawa K, Kuwajima S, Yoshioka N, Atsumi T, Hasunuma Y, Koike T: Advanced glycation endproducts and diabetic nephropathy. J Diabetes Complications 1995;9:265-268.

19 Uribarri J, Peppa M, Cai W, Goldberg T, Lu $\mathrm{M}, \mathrm{He} \mathrm{C}$, Vlassara H: Restriction of dietary glycotoxins reduces excessive advanced glycation endproducts in renal failure patients. J Am Soc Nephrol 2003;14:728-731.

20 Muntner P, Coresh J, Smith JC, Eckfeldt J, Klag MJ: Plasma lipids and risk of developing renal dysfunction: the atherosclerosis risk in communities study. Kidney Int 2000;58: 293-301.

21 Okamura DM, Pennathur S, Pasichnyk K, López-Guisa JM, Collins S, Febbraio M, Heinecke J, Eddy AA: CD36 regulates oxidative stress and inflammation in hypercholesterolemic CKD. J Am Soc Nephrol 2009;20: 495-505.

22 Wiggins JE, Goyal M, Wharram BL, Wiggins RC: Antioxidant ceruloplasmin is expressed by glomerular parietal epithelial cells and secreted into urine in association with glomerular aging and high-calorie diet. J Am Soc Nephrol 2006;17:1382-1387.

23 Cuervo AM, Bergamini E, Brunk UT, Dröge W, Ffrench M, Terman A. Autophagy and aging: the importance of maintaining 'clean' cells. Autophagy 2005;1:131-140.

24 Hartleben B, Gödel M, Meyer-Schwesinger C, Liu S, Ulrich T, Köbler S, Wiech T, Grahammer F, Arnold SJ, Lindenmeyer MT, Cohen CD, Pavenstädt H, Kerjaschki D, Mizushima N, Shaw AS, Walz G, Huber TB: Autophagy influences glomerular disease susceptibility and maintains podocyte homeostasis in aging mice. J Clin Invest 2010; 120:1084-1096.

25 Campisi J: Senescent cells, tumor suppression, and organismal aging: good citizens, bad neighbors. Cell 2005;120:513-522.

26 Westhoff JH, Schildhorn C, Jacobi C, Hömme M, Hartner A, Braun H, Kryzer C, Wang C, von Zglinicki T, Kränzlin B, Gretz $\mathrm{N}$, Melk A: Telomere shortening reduces regenerative capacity after acute kidney injury. J Am Soc Nephrol 2010;21:327-336.

27 Feest TG, Round A, Hamad S: Incidence of severe acute renal failure in adults: results of a community based study. BMJ 1993;306: 481-483.

28 Delahunt B, Stehbens WE, Gilbert-Barness E, Shozawa T, Rüger BM. Progeria kidney has abnormal mesangial collagen distribution. Pediatr Nephrol 2000;15:279-285.
29 Pawlikowska L, Hu D, Huntsman S, Sung A, Chu C, Chen J, Joyner AH, Schork NJ, Hsueh WC, Reiner AP, Psaty BM, Atzmon G, Barzilai N, Cummings SR, Browner WS, Kwok PY, Ziv E: Association of common genetic variation in the insulin/IGF1 signaling pathway with human longevity. Aging Cell 2009;8: 460-472.

30 Kenyon CJ: The genetics of ageing. Nature 2010;464:504-512.

31 Kapahi P, Zid B: TOR pathway: linking nutrient sensing to life span. Sci Aging Knowledge Environ 2004;2004:PE34.

32 Kapahi P, Chen D, Rogers AN, Katewa SD, Li PW, Thomas EL, Kockel L: With TOR, less is more: a key role for the conserved nutrientsensing TOR pathway in aging. Cell Metab 2010;11:453-465.

-33 Harrison DE, Strong R, Sharp ZD, Nelson JF, Astle CM, Flurkey K, Nadon NL, Wilkinson JE, Frenkel K, Carter CS, Pahor M, Javors MA, Fernandez E, Miller RA: Rapamycin fed late in life extends lifespan in genetically heterogeneous mice. Nature 2009;460:392-395.

- 34 Haigis MC, Sinclair DA. Mammalian sirtuins: biological insights and disease relevance. Annu Rev Pathol 2010;5:253-295.

35 Mostoslavsky R, Chua KF, Lombard DB, Pang WW, Fischer MR, Gellon L, Liu P, Mostoslavsky G, Franco S, Murphy MM, Mills KD, Patel P, Hsu JT, Hong AL, Ford E, Cheng HL, Kennedy C, Nunez N, Bronson R, Frendewey D, Auerbach W, Valenzuela D, Karow M, Hottiger MO, Hursting S, Barrett JC, Guarente L, Mulligan R, Demple B, Yancopoulos GD, Alt FW: Genomic instability and aging-like phenotype in the absence of mammalian SIRT6. Cell 2006;124:315-329.

36 Wang Y, Sun Z: Current understanding of klotho. Ageing Res Rev 2009;8:43-51.

37 Kuro-O M: Klotho and aging. Biochim Biophys Acta 2009;1790:1049-1058

- 38 Arking DE, Krebsova A, Macek Sr M, Macek Jr M, Arking A, Mian IS, Fried L, et al: Association of human aging with a functional variant of klotho. Proc Natl Acad Sci USA 2002;99:856-861

- 39 Liang H, Masoro EJ, Nelson JF, Strong R, McMahan CA, Richardson A: Genetic mouse models of extended lifespan. Exp Gerontol 2003;38:1353-1364.

40 Bartke A, Brown-Borg H: Life extension in the dwarf mouse. Curr Top Dev Biol 2004;63: 189-225. 